\title{
Integral Sliding Mode Control Based on Game-Theoretic Approach for UPS Inverters
}

\author{
En-Chih Chang, Hung-Liang Cheng, Rong-Ching $\mathrm{Wu}^{*}$ \\ Department of Electrical Engineering, I-Shou University, No.1, Sec. 1, Syuecheng Rd., Dashu District, \\ Kaohsiung City 84001, Taiwan, R.O.C. \\ * Corresponding author. Tel.: +886-7-6577711 Ext. 6636; email: rcwu@isu.edu.tw \\ Manuscript submitted October 11, 2018; accepted January 24, 2019. \\ doi: 10.17706/ijcee.2019.11.1.62-69
}

\begin{abstract}
An integral sliding mode control (ISMC) based on game-theoretic approach to effectuate the satisfactory performance under the large perturbations/strong nonlinearities is presented for UPS inverters. This proposed methodology provides a modified construction compared with the conventional SMC. The integral compensator is employed to eliminate the steady-state error for small error circumstance. The game-theoretic approach is introduced to design the proper sliding surface so that the system stability and speedy response can be gained. The combined methodology of the ISMC and game-theoretic approach can be well used in UPS inverter to carry out a high reliable performance, even under hard transient and steady-state conditions, such as sudden load changes and rectifier loads. An experimental exploration is given to support the theoretical considerations and simulation results.
\end{abstract}

Key words: Integral sliding mode control (ISMC), steady-state error, game-theoretic approach, speedy response, UPS inverter.

\section{Introduction}

Uninterruptible power supplies (UPS's) have been throughout used for the defense of sensitive loading, such as air traffic control systems, telecommunication centers and life support equipment in hospitals, against utility power failures. The competence of guaranteeing a low distorted output-voltage and fast transience in face of nonlinear loads (especially diode rectifiers with capacitive filter) and sudden load changes must be achieved [1]-[3]. In most applications, proportional-integral (PI) control can work well under linear load circumstances. However, the stable and reliable performance cannot be obtained while the plant is applied to fluctuating load perturbations [4], [5]. Numerous control means can be seen in research publications, such as dead-beat control, repetitive control, and H-infinity control [6]-[9]. Though the good results of these methods have been shown, it is difficult to attain both low total harmonic distortion (THD) of the output-voltage and the fast transient response. Proposed in 1950s, sliding mode control (SMC) is a robust technique for governing nonlinear system with uncertainties, that is to say, the property of a SMC has the insensitivity to internal parameter variations and external load perturbations [10]-[13]. The action of the SMC system can be depicted as follows: The trajectory of the state error is forced towards the predetermined sliding surface, and once the trajectory behaviour hits the sliding surface, it not only slides along the sliding surface to the equilibrium point but is independent of parametric uncertainties and external perturbations [14]-[16]. The sliding mode controlled UPS inverters are also reported in the literature [17]-[22]. A fixed switching frequency sliding mode is represented for single-phase inverters; the control design uses an 
orthodox sliding surface, producing the distortion of the output-voltage under nonlinear loads [17]. To regain the lost system dynamics of the grid-connected voltage source inverter, a multiple resonant object-based sliding surface is designed. The performance in steady-state and transience is improved, but this method is time-consuming calculation [18]. The modified SMC with the repression of the uncertain perturbation is proposed for voltage regulation in microgrids, however the hardware design is sophisticated and there is unwanted chatter problem [19]. In the case of trajectory tracking systems, the invariant properties represented by orthodox SMC are hold only during the sliding phase; the internal parameter variations/external load perturbations may influence the tracking behaviour in the reaching phase. Previous reports have attempted to accelerate the reaching time and reduce the tracking error. The reaching time can be shortened by using the observer methodology, but such way employs an orthodox reduced-order design, leading to large chatter which is undesirable in dynamic systems [20]. A time-varying sliding surface presented by a limitation with zero errors in the initial circumstances for the sake of lessening the reaching phase has been applied to the nonlinear system. Nevertheless, it does not satisfy the general condition because the initial circumstances may be arbitrarily appointed in the actual system [21]. The indirect sliding mode scheme is developed for the control of grid-connected power converters. Although this scheme provides the system state converged to the sliding surface within a short time, the phenomenon of the chattering around sliding surface occurs [22]. As above remarked [17]-[22], their ability in the low output-voltage distortion and a fast dynamic response can be manifested. But, if the system is exposed to large perturbations/rigorous nonlinearities, the orthodox sliding mode controlled system has to be modified otherwise the inexact tracking behaviour may exist. Integral compensator for eliminating the steady-state error can be utilized when subjected to large disturbances. The coalition of integral compensator and SMC, known as integral sliding mode control (ISMC) is therefore presented to achieve the steady-state accuracy and strong robustness [23], [24]. Furthermore, an appropriate design to the sliding surface of the ISMC by using game-theoretic approach is introduced. The game-theoretic approach is proposed from approximately 1950. It can be viewed as the investigation of pursuit-evasion between two objectives movement according to simple kinematic laws [25]-[27]. For example, we can appoint that the control strategy stands for the pursuit and the perturbation signifies the evasion. The design of the sliding surface will deal properly with the state energy during the sliding process that is minimized [28]-[30]. Hence, this control methodology can be applied to control an UPS system in which the control law is implemented on a Texas Instruments DSP and has shown the efficacy of low output-voltage distortion, good voltage regulation and insensitive to the load perturbation even under rectified loading. The beginning of this paper illustrates the dynamic model of the UPS inverter. Next, integral sliding mode control based on game-theoretic approach is derived. Both simulation and experimental results are finally displayed to substantiate the transient and steady-state performance of the proposed methodology.

\section{Dynamic Modeling of the UPS Inverter}

Fig. 1 depicts a generally used UPS inverter, which is composed of an LC filter and switching component with IGBT transistors. The load can be any types: resistance, inductance, capacitor, nonlinear, etc. These loads can be applied to test the performance of the UPS inverter, and the output-voltage is designed to produce 110 $V_{\text {rms }}$ with $60 \mathrm{~Hz}$ frequency.

Using the KVL and KCL, the dynamic equations of the UPS inverter can be stated as

$$
\begin{gathered}
L \frac{d i_{L}}{d t}+v_{O}=K_{p w} v_{c o n} \\
i_{L}=C \frac{d v_{O}}{d t}+\frac{v_{O}}{R}
\end{gathered}
$$


where $K_{p w}=V_{S} / \hat{v}_{t r}$ is the equivalent gain of the inverter, $V_{S}$ stands for the DC supply voltage, $\hat{v}_{t r}$ represents the amplitude of the triangular wave, and $v_{c o n}$ symbols the control signal.

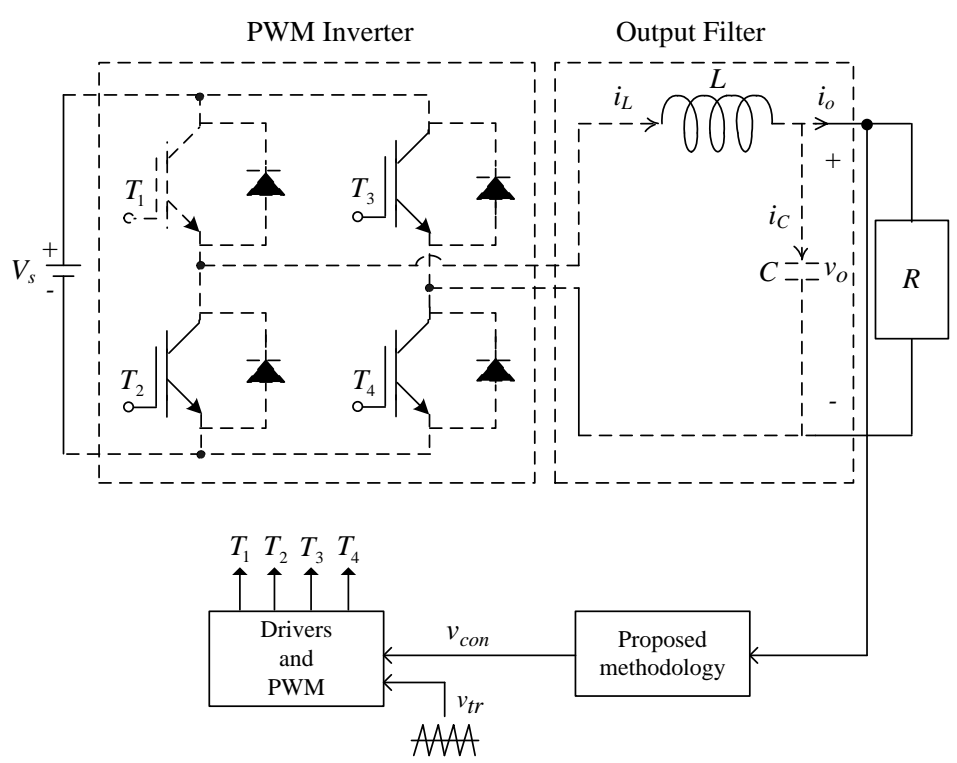

Fig. 1. UPS inverter and its controller.

From (1) and (2), the differential equation can be formulated as

$$
\ddot{v}_{O}=-\frac{1}{R C} \dot{v}_{O}-\frac{1}{L C} v_{O}-\frac{K_{p w}}{L C} v_{c o n}
$$

Letting $x=\left[\begin{array}{ll}x_{1} & x_{2}\end{array}\right]=\left[\begin{array}{ll}v_{o} & \dot{v}_{o}\end{array}\right]$, the (3) can be expressed as

$$
\left[\begin{array}{l}
\dot{x}_{1} \\
\dot{x}_{2}
\end{array}\right]=\left[\begin{array}{cc}
0 & 1 \\
-\frac{1}{L C} & -\frac{1}{R C}
\end{array}\right]\left[\begin{array}{l}
x_{1} \\
x_{2}
\end{array}\right]+\left[\begin{array}{c}
0 \\
\frac{K_{p w}}{L C}
\end{array}\right] v_{c o n}
$$

Practically, the load is not a pure resistance and it is uncertainty and nonlinearity. We can define the following relationship:

$$
\text { Loadconditions } s=\left\{\begin{array}{l}
\text { Pure resistance } \quad, R_{r}=R \text { and } \Delta R_{n}=0 \\
\text { Unknownloading }, R_{r}=R+\Delta R_{n} \text { and } \Delta R_{n} \neq 0
\end{array}\right.
$$

For the unknown loading with resistance $R_{r}$ and uncertainty $\Delta R_{n}$, the plant model of the UPS inverter can be rewritten as

$$
\begin{aligned}
{\left[\begin{array}{c}
\dot{x}_{1} \\
\dot{x}_{2}
\end{array}\right] } & =\underbrace{\left[\begin{array}{cc}
0 & 1 \\
-\frac{1}{L C} & -\frac{1}{\left(R_{r}+\Delta R_{n}\right)+C}
\end{array}\right]}_{A}\left[\begin{array}{l}
x_{1} \\
x_{2}
\end{array}\right]+\underbrace{\left[\begin{array}{c}
0 \\
\frac{K}{L w}
\end{array}\right]}_{B} v_{c o n} \\
& =\left\{A_{p} x_{p}+B_{p} u\right\}+\left\{A_{e} x_{e}+B_{e} v\right\}
\end{aligned}
$$

where $x=x_{p}+x_{e}, A=A_{p}+A_{e}, B=B_{p}+B_{e}, v_{c o n}=u+v$.

Owing to the perturbation $\Delta R_{n}$ is uncertain, the game-theoretic design can be adopted to make the 
controlled UPS inverter withstand the load uncertainty while preserving low distorted output-voltage and achieving good transient and steady-state performance.

\section{Controller Design}

The real UPS inverter system can be restated as

$$
\begin{aligned}
& \dot{x}_{p}=A_{p}(t) x_{p}+B_{p}(t) u \\
& \dot{x}_{e}=A_{e}(t) x_{e}+B_{e}(t) v
\end{aligned}
$$

where $x_{p}, x_{e}$ are the states of the pursuer and evader, $u, v$ represent the controls of the pursuer and evader, and $A_{p}, A_{e}$ stand for the matrices, respectively. The distance between pursuer and evader can be written as $\left\|x_{p}-x_{e}\right\|_{\sigma^{T} \sigma}^{2}$, where $\sigma$ is a positive definite matrix.

The integral sliding surface can be chosen as

$$
z(t) \equiv \int \sigma\left(x_{p}^{n e w}(t)-x_{e}^{n e w}(t)\right)
$$

where $x_{p}^{n e w}, x_{e}^{\text {new }}$ indicate the new variables of the pursuer and evader.

If there is a performance index $J$ and it can be transformed into a Hamiltonian function $H$, the strategic requirement of the pursuer and evader yields

$$
\frac{\partial H}{\partial u}=\frac{\partial H}{\partial v}=0
$$

Also, the (11) has to hold as follows:

$$
\frac{\partial^{2} H}{\partial u^{2}}=R_{p}>0, \frac{\partial^{2} H}{\partial v^{2}}=-R_{e}<0
$$

where $R_{p}$ and $R_{e}$ are constants. Therefore, $u$ ensures $J$ minimum, and $v$ makes $J$ maximum.

\section{Simulation and Experimental Results}

The simulation and experimental proof of the proposed methodology are performed on a UPS inverter with the specifications displayed in Table 1.

Table 1. System Parameters

\begin{tabular}{lc}
\hline DC voltage & $200 \mathrm{~V}$ \\
Filter capacitor & $2.5 \mu \mathrm{F}$ \\
Filter inductor & $0.2 \mathrm{mH}$ \\
Switching frequency & $18 \mathrm{kHz}$ \\
Output voltage and frequency & $110 V_{r m s}, 60 \mathrm{~Hz}$ \\
\hline
\end{tabular}

\subsection{Simulation Results}

Simulations are carried out using the Matlab/Simulink software. Fig. 2(a) show the transient response of 
the simulated output-voltage under step change in load from no-load to $\mathrm{R}=12 \Omega$. The satisfactory transience can be seen, i.e., the instantaneous output-voltage sag is small and there is a fast recovery time. Fig. 2(b) shows the simulated output-voltage under when the nonlinear load is a diode bridge rectifier with a capacitor filter $(120 \mu \mathrm{F})$ and a parallel resistor $(25 \Omega)$. It can be explored that the output-voltage is little affected by the load perturbation; the steady-state response of the UPS inverter shows an almost sinusoidal waveform. The computed \%THD equals $1.01 \%$, and the amplitude of the output-voltage is close to $110 \mathrm{Vrms}$, respectively.

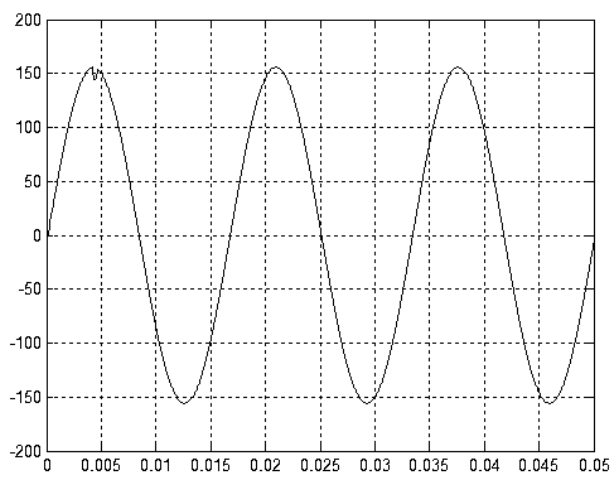

(a)

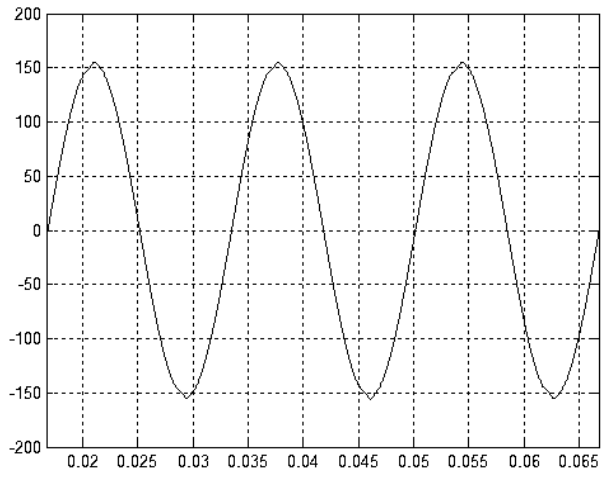

(b)

Fig. 2. Output-voltage waveforms of the proposed UPS inverter under (a) turn-on of a resistive load. (b) rectifier load.

\subsection{Experimental Results}

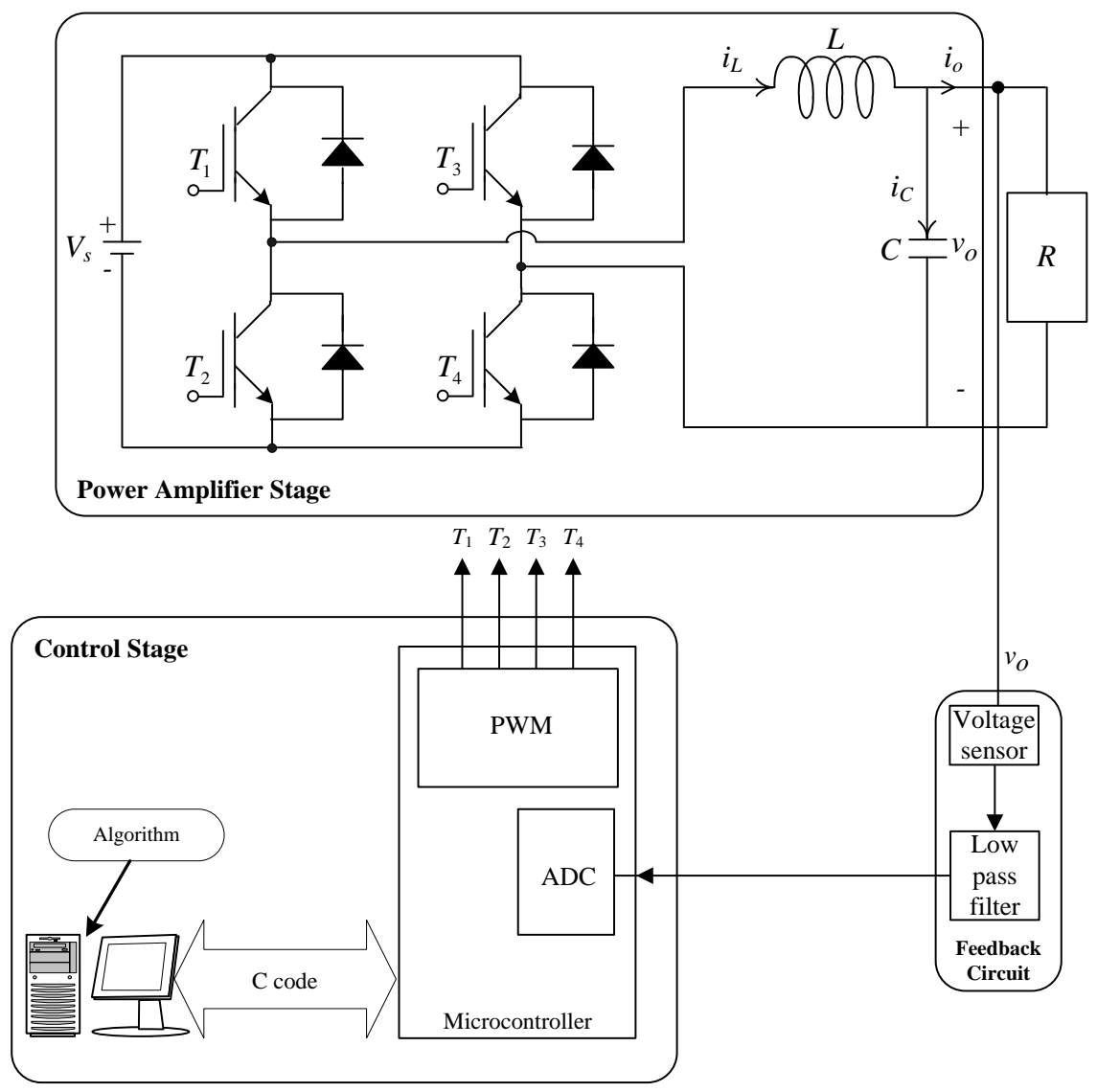

Fig. 3. Hardware construction. 
To confirm the effectiveness of the proposed methodology, a laboratory prototype with TMS320F28335-based digital controller has been designed and implemented. The realization of the hardware construction is displayed as Fig. 3. Four optical couples (PC923) are used to ensure isolation between the control and power circuits. The power IGBT transistors are employed as switching components. The voltage sensor used is AD202 isolation amplifier. The experiments for UPS inverter under various circumstances are performed to illustrate good performance of the proposed methodology. Fig. 4(a) shows the experimental output-voltage of the proposed methodology under full-load circumstance $(R=12 \Omega)$. The output-voltage is nearly sine wave with negligible distortion. Additionally, the experimental output-voltage of the proposed UPS inverter under sudden load change form no-load to full-load is represented in the Fig. 4(b). We can find that the proposed UPS inverter has small output-voltage sag with fast retrieval.

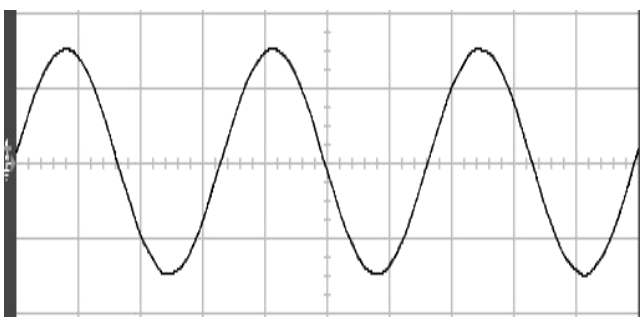

(a)

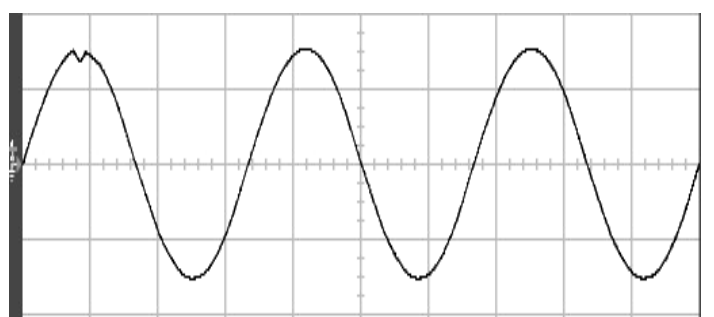

(b)

Fig. 4. Output-voltage waveforms of the proposed UPS inverter (a) full load. (b) sudden load change from no load to full load.

\section{Conclusion}

The SMC provides strong robustness to internal parameter variations and external load perturbations. The integral compensation can be introduced into the SMC to eliminate the steady-state error. By combining the integral compensation and SMC, the control law of the ISMC yields. In addition, the game-theoretic approach is applied in ISMC to design the proper sliding surface in the presence of the uncertain perturbations. With this proposed methodology, the UPS inverter under linear loading and nonlinear loading can achieve the more robust performance. The theoretical analysis has been provided, and the simulated and experimental results are also given to demonstrate the proposed UPS inverter.

\section{Acknowledgment}

This work was supported by the Ministry of Science and Technology of Taiwan, R.O.C., under contract number MOST107-2221-E-214-006.

\section{References}

[1] Hart, D. W. (2010). Power Electronics. New York: McGraw-Hill.

[2] Wilamowski, B. M., \& Irwin, J. D. (2011). Power Electronics and Motor Drives. Boca Raton: CRC Press.

[3] Luo, F. L., \& Ye, H. (2010). Power Electronics: Advanced Conversion Technologies. Boca Raton: CRC Press.

[4] Caceres, R., Rojas, R., \& Camacho, O. (2000). Robust PID control of a buck-boost DC-AC converter. Proceedings of the International Telecommunications Energy Conference (pp. 180-185).

[5] Cha, H. I., Kim, S. S., Kang, M. G., \& Chung, Y. H. (1990). Real-time digital control of PWM inverter with PI compensator for uninterruptible power supply. Proceedings of the IEEE Industrial Electronics Society (pp. 1124-1128).

[6] Zhang, X. G., Zhang, W. J., Chen, J. M., \& Xu, D. G. (2014). Deadbeat control strategy of circulating currents in parallel connection system of three-phase PWM converter. IEEE Trans. on Energy Conversion, 29(2), 
406-417.

[7] Hu, J. B., \& Zhu, Z. Q. (2013). Improved voltage-vector sequences on dead-beat predictive direct power control of reversible three-phase grid-connected voltage-source converters. IEEE Trans. on Power Electronics, 28(1), 254-267.

[8] Zhang, B., Zhou, K. L., \& Wang, D W. (2014). Multirate repetitive control for PWM DC/AC converters. IEEE Trans. on Industrial Electronics, 61(6), 2883-2890.

[9] Howlader, M., Urasaki, N., Yona, A., Senjyu, T., \& Saber, A. Y. (2013). Design and implement a digital H-infinity robust controller for a MW-class PMSG-based grid-interactive wind energy conversion system. Energies, 6(4), 2084-2109.

[10] Utkin, V. I. (1978). Sliding Modes and Their Applications in Variable Structure Systems. Moscow: Mir.

[11] Azar, A. T., \& Zhu, Q. M. (2015). Advances and Applications in Sliding Mode Control Systems. New York: Springer.

[12] Wu, L. G., Shi, P., \& Su, X. J. (2014). Sliding Mode Control of Uncertain Parameter-Switching Hybrid Systems. New York: Wiley.

[13] Sira-Ramirez, H. (1989). Sliding regimes in general non-linear systems: a relative degree approach. International Journal of Control, 50(4), 1487-1506.

[14] Doulgeri, Z. (1999). Sliding regime of a nonlinear robust controller for robot manipulators. IEEE Control Theory and Applications, 146(6), 493-498.

[15] Stanchev, S. P. (2003). A variant of an (combined) adaptive controller design introducing sliding regime in Lyapunov derivative. Proceedings of the IEEE American Control Conference (pp. 909-914).

[16] Vaidyanathan, S., \& Lien, C. H. (2017). Applications of Sliding Mode Control in Science and Engineering. New York: Springer.

[17] Abrishamifar, A., Ahmad, A. A., \& Mohamadian, M. (2012). Fixed switching frequency sliding mode control for single-phase unipolar inverters. IEEE Trans. on Power Electronics, 27(5), 2507-2514.

[18] Hao, X., Yang, X., Liu, T., Huang, L., \& Chen, W. J. (2013). A sliding-mode controller with multiresonant sliding surface for single-phase grid-connected VSI with an LCL filter. IEEE Trans. on Power Electronics, 28(5), 2259-2268.

[19] Aghatehrani, R., \& Kavasseri, R. (2013). Sensitivity-analysis-based sliding mode control for voltage regulation in microgrids. IEEE Trans. on Sustainable Energy, 4(1), 50-57.

[20] Camila, L. C., Tiago, R. O., \& Jose, P. V. S. C. (2013). Output-feedback sliding-mode control of multivariable systems with uncertain time-varying state delays and unmatched non-linearities. IET Control Theory and Applications, 7(12), 1616-1623.

[21] Hung, L. C., Lin, H. P., \& Chung, H. Y. (2007). Design of self-tuning fuzzy sliding mode control for TORA system. Expert Systems with Applications, 32, 201-212.

[22] Hemdani, A., Dagbagi, M., Naouar, W. M., Idkhajine, L., Belkhodja, I. S., \& Monmasson, E. (2015). Indirect sliding mode power control for three phase grid connected power converter. IET Power Electronics, 8(6), 977-985.

[23] Chern, T., \& Wu, Y. (1991). Design of integral variable structure controller and application to electrohydraulic velocity servo systems. IEEE Electrical Power Applications, 138(5), 439-444.

[24] Sbarbaro, D. (1996). Application of integral variable structure controller. Proceedings of the IEEE Conference on Industrial Electronics and Applications (pp. 673-678).

[25] Basar, T., \& Olsder, G. J. (1982). Dynamic Noncooperative Game Theory. London: Academic Press.

[26] Mei, S. W., Wei, W., \& Liu, F. (2017). On engineering game theory with its application in power systems. Control Theory and Technology, 15(1), 1-12.

[27] Faycal, E. K., Fatima, Z. G., \& Fatiha, L. (2013). Applications of cooperative game theory in power system 
allocation. Leonardo Journal of Sciences, 23, 125-136.

[28] Farzaneh, P., Mahmud F. F., \& Payman, D. (2017). Application of game theory in reliability-centered maintenance of electric power systems. IEEE Trans. on Industry Applications, 53(2), 936-946.

[29] Vikas, K., Savita, N. \& Prashant, B. (2012). Application of game theory in PV-wind hybrid system. International Journal of Electrical and Electronics Engineering Research, 2(4), 25-32.

[30] Martin, J. O. (2010). Introduction to Game Theory. London: Oxford University Press.

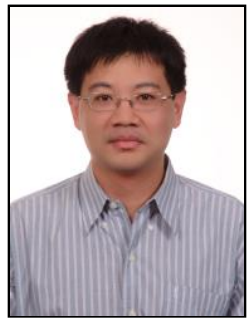

En-Chih Chang was born in Kaohsiung, Taiwan, in 1975. He received his B.S. degree from Feng-Chia University, Taichung, Taiwan, ROC, in 1999; his M.S. degree from the National Taiwan Ocean University, Keelung, Taiwan, ROC, in 2001; and his Ph.D. degree from the National Cheng Kung University, Tainan, Taiwan, ROC, in 2008, all in electrical engineering. $\mathrm{He}$ is presently working as an associate professor in the Department of Electrical Engineering, I-Shou University, Kaohsiung, Taiwan, ROC. His current research interests include sliding mode control, intelligent control, grey theory, and their applications in power electronics systems.

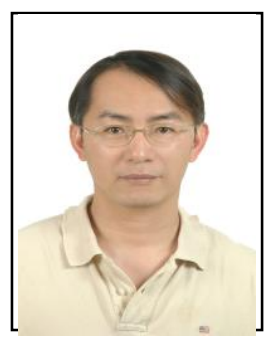

Hung-Liang Cheng was born in Chunghwa, Taiwan, in 1964. He received the B.S., M.S., and Ph.D. degrees in electrical engineering from the National Sun Yat-Sen University, Kaohsiung, Taiwan, in 1986, 1988, and 2001, respectively. From 1988 to 2007, he was an electronic researcher with the Chung-Shan Institute of Science and Technology, Taoyuan County, Taiwan, where he designed and developed high-power transmitters in radar and missile systems. Since February 2007, he has been with I-Shou University, Kaohsiung, Taiwan, where he is currently a professor in the Department of Electrical Engineering. His current research interests include power-electronic converters and electronic ballasts/drivers for lighting applications. Prof. Cheng is memberships of the IEEE Industrial Electronics Society and the IEEE Power Electronic Society.

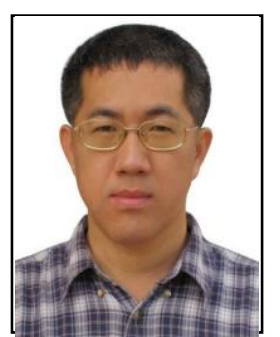

Rong-Ching Wu graduated from National Taiwan Institute of Technology, Taipei, Taiwan, in 1990. He received the M.Sc. degree in 1994 and received the Ph.D. degree in 2001 from National Sun Yat-Sen University, Kaohsiung, Taiwan, R.O.C. From 1991 to 2001, he was an electrical engineer in Taiwan Power Company, Kaohsiung, Taiwan, and was involved with design, construction, and operation of power systems. Currently, he is an associate professor at I-Shou University, Kaohsiung, Taiwan, R.O.C. 